\title{
Gestational diabetes and the risk of late stillbirth: a case- control study from England, UK
}

DOI:

10.1111/1471-0528.15659

\section{Document Version}

Accepted author manuscript

Link to publication record in Manchester Research Explorer

\section{Citation for published version (APA):}

Stacey, T., Tennant, P., McCowan, L. M. E., Mitchell, E. A., Budd, J., Li, M., Thompson, J. M. D., Martin, B., Roberts, D., \& Heazell, A. (2019). Gestational diabetes and the risk of late stillbirth: a case-control study from England, UK. British Journal of Obstetrics and Gyanecology. https://doi.org/10.1111/1471-0528.15659

\section{Published in:}

British Journal of Obstetrics and Gyanecology

\section{Citing this paper}

Please note that where the full-text provided on Manchester Research Explorer is the Author Accepted Manuscript or Proof version this may differ from the final Published version. If citing, it is advised that you check and use the publisher's definitive version.

\section{General rights}

Copyright and moral rights for the publications made accessible in the Research Explorer are retained by the authors and/or other copyright owners and it is a condition of accessing publications that users recognise and abide by the legal requirements associated with these rights.

\section{Takedown policy}

If you believe that this document breaches copyright please refer to the University of Manchester's Takedown Procedures [http://man.ac.uk/04Y6Bo] or contact uml.scholarlycommunications@manchester.ac.uk providing relevant details, so we can investigate your claim.

\section{OPEN ACCESS}


Title page

2

3 Gestational diabetes and the risk of late stillbirth: a case-control study from England, UK

4 Tomasina Stacey (1), Peter WG Tennant (2,3,4), Lesley ME McCowan (5), Edwin A Mitchell (6), Jayne

5 Budd (7, 8), Minglan Li (5), John M D Thompson (5,6), Bill Martin (9), Devender Roberts (10),

$6 \quad$ Alexander EP Heazell $(7,8)$

7 1. School of Healthcare, University of Leeds, Leeds, United Kingdom

8 2. Leeds Institute for Data Analytics, University of Leeds, Leeds, United Kingdom

9 3. School of Medicine, University of Leeds, Leeds, United Kingdom

10 4. The Alan Turing Institute, London, United Kingdom

11 5. Department of Obstetrics and Gynaecology, The University of Auckland, Auckland, New Zealand

12 6. Department of Paediatrics: Child and Youth Health, The University of Auckland, Auckland, New

13 Zealand.

14 7. Maternal and Fetal Health Research Centre, School of Medical Sciences, Faculty of Biological,

15 Medical and Human Sciences, University of Manchester, United Kingdom

16 8. St. Mary's Hospital, Manchester University NHS Foundation Trust, Manchester Academic Health

17 Science Centre, Manchester, United Kingdom

18 9. Birmingham Women's Hospital NHS Foundation Trust, Mindelsohn Way, Edgbaston, Birmingham,

19 United Kingdom

20 10. Liverpool Women's Hospital NHS Foundation Trust, Crown Street, Liverpool, United Kingdom.

22 Corresponding author: Tomasina Stacey t.stacey@leeds.ac.uk

23 School of Healthcare, University of Leeds,

24 Baines Wing, Woodhouse House

25 Leeds, LS2 9JT

26 United Kingdom 
$+44(0) 1133431252$

28 Running title: Gestational diabetes and the risk of late stillbirth

29

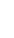


Objective - To explore the separate effects of being at risk of gestational diabetes mellitus (GDM) and screening for GDM, and of raised fasting plasma glucose (FPG) and clinical diagnosis of GDM, on the risk of late stillbirth.

Design - Prospective case-control study.

Setting - 41 maternity units in the United Kingdom.

Population - Women who had a stillbirth $\geq 28$ weeks' gestation $(n=291)$ and women with an ongoing pregnancy at the time of interview $(n=733)$.

Methods - Causal mediation analysis explored the joint effects of 1) 'at risk' of GDM and screening for GDM and 2) raised FPG ( $\geq 5.6 \mathrm{mmol} / \mathrm{L})$ and clinical diagnosis of GDM on the risks of late stillbirth. Adjusted odds ratios (aOR) were estimated by logistic regression adjusted for confounders identified by directed acyclic graphs.

Main outcome measures - Screening for GDM and FPG levels

Results -Women 'at risk' of GDM, but not screened, experienced $44 \%$ greater risk of late stillbirth than those not at risk (aOR=1.44 95\%Cl=1.01-2.06). Women 'at risk' of GDM who were screened experienced no such increase $(\mathrm{aOR}=0 \cdot 98,95 \% \mathrm{Cl}=0 \cdot 70-1 \cdot 36)$. Women with raised FPG not diagnosed with GDM experienced four-fold greater risk of late stillbirth than women with normal FPG

$47(\mathrm{aOR}=4 \cdot 22,95 \% \mathrm{Cl}=1 \cdot 04-17 \cdot 02)$. Women with raised FPG who were diagnosed with GDM experienced no such increase $(\mathrm{aOR}=1 \cdot 1095 \% \mathrm{Cl}=0 \cdot 31-3 \cdot 91)$.

49 Conclusions - Optimal screening and diagnosis of GDM mitigates higher risks of late stillbirth in 50 women at risk of GDM and/or with raised FPG. Failure to diagnose GDM leaves women with raised 51 FPG exposed to avoidable risk of late stillbirth.

52 Funding - The Midland and North of England Stillbirth Study was funded by grant GN2156 from 53 Action Medical Research, Cure Kids and Sands. 
55 Tweetable abstract: Risk of \#stillbirth in gestational diabetes is mitigated by effective screening and 56 diagnosis.

57

58 Keywords: Stillbirth, gestational diabetes mellitus, pregnancy

\section{9}

60 Abbreviations:

$61 \quad$ FPG Fasting plasma glucose

62 GDM Gestational diabetes mellitus

63 IADPSG International Association of Diabetes and Pregnancy Study Groups

64 OGTT Oral glucose tolerance test

65 OR Odds ratio

66 WHO World Health Organisation

67

68 
70 The prevalence of stillbirth in the United Kingdom (UK) is above the European average, affecting 71 almost one in three hundred pregnancies after 28 weeks of pregnancy.[1] Though likely influenced by a higher burden of population risk factors, such as obesity and cigarette smoking-compared to some countries with lower rates of late stillbirth, a recent Confidential Enquiry concluded that up to $60 \%$ of antepartum stillbirths could have been prevented with improved antenatal care.[2] Of particular concern was a lack of consistent adherence to the National Institute for Health and Care Excellence (NICE) guidelines for the screening and diagnosis of gestational diabetes (GDM) [3], which recommends that all women with one or more risk factor for GDM (South Asian or Black Caribbean ethnicity, body mass index (BAI) $\geq 30 \mathrm{Kg} / \mathrm{m}^{2}$, previous pregnancy affected by GDA or macrosomic birth, and family history of diabetes) have a $75 \mathrm{~g} 2$ hour Oral Glucose Tolerance Test (OGTI) at $24-26$ weeks of pregnancy.[3]. Early identification and appropriate management of GDM has been considered an important factor in reducing the burden of adverse perinatal outcome.[4, 5] Hence, the Confidential Enquiry recommended an increased focus on the detection and management of GDM.[2] Pre-existing (Type 1 or type 2) diabetes in pregnancy is associated with a four-to-six-fold increase in the risk of stillbirth.[4ㅌ]_-However, $[$ - the relationship between GDM and risk of -stillbirth is more complex; with no consensus in the relationship between GDM and risk of stillbirth.-[4, 7-8] studies have either suggested that GDM is associated with an increased risk [5] or found no difference in the risk of stillbirth, [6] with one study even finding a protective association between diagnosis of gestational diabetes and stillbirth.[7]-These studies employed a range of diagnostic criteria for GDM and there is inconsistency as to whether or not they have-included women who were diagnosed with GDM fand therefore received enhanced care)-or who, retrospectively ${ }_{L}$ met the criteria for GDM diagnosis. Early identification and appropriate management of GDA has been considered an developing GDM. $[6,8]$ 
95 There is variation in recommendations regarding which women should be screened for GDM as well 96 as differences in the criteria used for the diagnosis of GDM., with recent changes to the 97 internationally recommended criteria for diagnosis of GDM. [9, 10] Following extensive research, [11] the International Association of Diabetes and Pregnancy Study Groups (IADPSG) recommended that GDM be diagnosed for fasting plasma glucose (FPG) concentrations $\geq 5.1 \mathrm{mmol} / \mathrm{l}, \geq 10 \mathrm{mmol} / \mathrm{l}$ hour or $\geq 8.5 \mathrm{mmol} / / 2$-hours after $75 \mathrm{~g}$ oral glucose tolerance test (OGTT). [10] These diagnostic criteria have since been adopted by the World Health Organisation (WHO).[12]-In the UK, the 2015 NICE guidelines insted-advised selected screening for GDM and the criteria recommended for GDM diagnosis afsare $F P G \geq 5.6 \mathrm{mmol} / \mathrm{L}$ or 2-hour glucose on the $\mathrm{OGTT} \geq 7.8 \mathrm{mmol} / \mathrm{L}$, which differs from the World Health Organisation (WHO) recommendations ( $\geq 5.1 \mathrm{mmol} / \mathrm{Lt}$ and $\geq 8.5 \mathrm{mmol} / \mathrm{Lt}$ ) [3, 10]-[3]. The rationale for this was to balance the benefits of increased detection of women with a higher risk of adverse outcomes with the health economics relating to the cost and capacity limits of antenatal care provision.[1311]_It is noted that the Hyperglycemia and Adverse Pregnancy Outcome (HAPO) study found a continuous relationship between all glucose levels in the OGTT and adverse pregnancy outcome.[14]-To date there has been no assessment of the impact of the thresholds recommended by NICE, nor on the impact of screening practice in the UK on the prevalence of late stillbirth. We aimed to investigate the joint and separate effects of 1) being at risk of GDM and

112 receiving blood glucose screening for GDM and 2) hyperglycaemia and diagnosis of GDM (as a proxy 113 for receiving specialised diabetes care) on the risk of late stillbirth in a large case-control study from 114 across England.

\section{Methods}

\section{Population and sample}

118 The Midlands and North of England Stillbirth Study (MiNESS) is a case-control study of singleton non119 anomalous late stillbirths ( $\geq 28$ weeks' gestation) and controls with ongoing pregnancies which 
ended in live births that were recruited in 41 maternity units in the UK between April 2014 and March 2016. It was principally established to explore the association between modifiable factors including maternal going-to-sleep position and the risk of late stillbirth.[12] The study was registered on www.clinicaltrials.gov (NCT02025530) and the protocol was published before data collection was complete.[15 13 ] Ethical and research approvals were obtained (Ref 13/NW/0874) on 20/01/14, with all participants providing written consent to take part in the study. MiNESS arose from the parentled Stillbirth Summit in Minneapolis in 2011 [14] and a Priority Setting Partnership which included input from over 550 parents and members of the public. However, there was no active patient involvement in data the-analyses or interpretation of this secondary analysis.

Inclusion and exclusion criteria

Full details of the study are available elsewhere.[1612] Briefly, cases were stillbirths occurring in singleton pregnancies $\geq 28$ complete weeks' of gestation. Prior to their discharge from the maternity unit eligible women were given information about the study and asked whether a researcher (who was also either a midwife or a nurse) could contact them to discuss the study. If the woman agreed, the researcher contacted her separately and, if consent was given to participate, an appointment for an interview was made. Participants were interviewed by research midwives or nurses at each site. Controls were women with an ongoing pregnancy at a similar gestational age to the cases. Controls were randomly selected (using a computer-generated sequence of random numbers) from the booking lists of each participating maternity unit based (on a 2:1 ratio) on the number and gestation of late stillbirths in the previous four years in that hospital. Controls were introduced to the study by their community midwife or a research midwife and a similar consent process to the cases was carried out. Multiple pregnancies or pregnancies complicated by congenital anomaly were not eligible for recruitment, neither were pregnancies where the mother was aged under 16 years or could not give informed consent.[153] Pregnancies where the mother had pre-existing (type 1 or type 2) diabetes were also excluded from the current sample. 
The separate effects of being 'at risk' of GDM and receiving blood glucose screening for GDM (and all consequences thereof) on the risk of stillbirth were examined by causal mediation analysis in the total study sample $(\mathrm{N}=1012) \cdot[17 \underline{15}]$ This approach, rooted in the potential outcome framework, involves evaluating examining how the occurrence of the an outcome $(\mathrm{Y})$ across-varies with more than one exposure, various theoretical (counterfactual) levels of thesuch as an exposure $\left(\left.Y\right|_{X=x}=Y_{x}\right)$ and mediator $\left(\left.Y\right|_{X=x, M=m}=Y_{x} M_{m}\right)$. This enables the distinct and joint effects of-e.g. the exposure and mediator to be estimated.

A composite exposure variable denoting 'at risk' of GDM was constructed from four of the five NICE recommended criteria for blood glucose screening for GDM, with 'at risk' defined as any of South Asian or Black Caribbean ethnicity, BMI $\geq 30 \mathrm{~kg} / \mathrm{m}^{2}$, or previous pregnancy effected by GDM or macrosomic ( $\geq 4.5 \mathrm{~kg}$ ) birth.[3] Data were not available on the fifth criterion, family history of GDM. The effects of exposure and mediator on the relative risk ratio of late stillbirth were estimated from odds ratios (ORs) calculated by logistic regression. 'At risk' of GDM was the principal exposure and receipt of screening for GDM was the principal mediator. Interactions terms were omitted due to negligible evidence of effect ( $p$-for-interaction=0-932). Confounding variables were identified by specifying directed acyclic graphs (DAGs) (Figure S1). No variables were considered appropriate for adjustment as all partial confounding variables were concurrent partial mediators.

The separate effects of hyperglycaemia and diagnosis of GDM (as a proxy for receiving specialist diabetes care) on the risk of stillbirth were also examined by causal mediation analysis, in all women

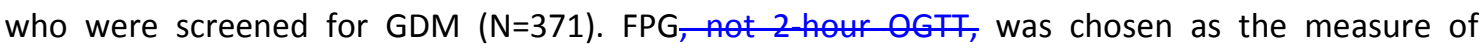
underlying glycaemic control, because of much lower concordance with $31.3 \%(n=5 / 16)$ of screened participants with an $F P G \geq 5.6 \mathrm{mmol} / \mathrm{L}$ were not clinically diagnosis-diagnosed of with GDM during pregnancy, compared with just $; 94 \cdot 15.9 \%(n=322 / 34)$ of those with a 2 -hour OGTT $\geq 7 \cdot 8 \mathrm{mmol} / \mathrm{L}$ ) 
170 received a clinicaldiagnosis of GDM-compared with $69.4 \%$ (n-11/16) with an FPG $\geq 5 \cdot 6 \mathrm{mmol} / \mathrm{t}$. This

171 discordance variation in practice allows the distinct effects of the underlying glycaemic control and

172 subsequent clinical diagnosis with GDM to be explored; as different combinations of both the

173 exposure and mediator can be observed. FPG concentration was the principal exposure and clinical

174 diagnosis of GDM was the principal mediator. Two models were evaluated; to explore FPG as a

binary variable and continuous variable. Binary FPG concentration was defined using the 2015 NICE

criteria for GDM diagnosis into 'normal' (FPG $<5 \cdot 6 \mathrm{mmol} / \mathrm{L}$ ) and 'raised' (FPG $\geq 5 \cdot 6 \mathrm{mmol} / \mathrm{L}$ ). Prior to

2015, the NICE criteria for the diagnosis of GDM by FPG was $\geq 7 \cdot 0 \mathrm{mmol} / \mathrm{L}$. The shape of the

association between continuous FPG concentration and risk of late stillbirth was examined by

locally-weighted scatterplot smoothing (LOWESS) (Figure 2). Interactions terms were again omitted

due to negligible evidence of effect ( $p$-for-interaction=0..772 for binary FPG, $p=0 . .501$ for continuous

FPG). Our DAG (Figure S1) implied the following confounding variables required adjustment:

maternal ethnicity, socio-economic circumstances, family history of GDM, height, weight, age,

parity, previous histories of GDM and macrosomia, and smoking. Family history of GDM was

however not known and is therefore a potential source of unobserved confounding.

Adjusted odds ratios (aORs) for the following causal effects were estimated by combining marginal

values within each multivariable logistic regression model (further descriptions of each are available

in the glossary): 1) the natural effect $\left.\left(Y_{1} M_{m \mid y=1}-Y_{0} M_{m \mid y=0}\right), 2\right)$ the total effect $\left.\left(Y_{1} M_{1}-Y_{0} M_{0}\right), 3\right)$ the

controlled direct effect $\left(Y_{1} M_{0}-Y_{0} M_{0}\right)$, 4) the total indirect effect $\left(Y_{1} M_{1}-Y_{1} M_{0}\right)$, and 5) the natural

indirect effect $\left.\left(\left[Y_{1} M_{m \mid y=1}-Y_{0} M_{m \mid y=10}\right] / f\right]-\left[Y_{1} M_{0}-Y_{0} M_{0}\right]\right)$. Causal effect estimates for mediators 'screening

for GDM' and 'diagnosis with GDM' comprise all the consequences thereof. They should not

therefore be interpreted as the isolated effect of e.g. 'diagnosis', but as everything that 'diagnosis'

typically effects (i.e. receipt of enhanced care and management).

95\% confidence intervals $(95 \% \mathrm{Cls})$ were derived using the delta method. We do not report total 
197 were available for $96.6 \%$ of total participants $(N=978 / 1012)$ and $91.9 \%(N=341 / 371)$ of those

198 screened for GDM. Sensitivity analyses were however conducted in multiply imputed data and negligible differences were observed (see Tables S1-4). For these sensitivity analyses; 50 datasets were generated via multivariate imputation by chained equations comprising case/control status, maternal age, height, weight, parity, education, ranked index of multiple deprivation (an area-based measure of socio-economic deprivation derived from the mother's residential postcode), ethnicity, country of birth, first language, FPG, 2-hour OGTT, and glycated haemoglobin concentrations, smoking and marital status, and previous histories of GDM and macrosomia. Point estimates and standard errors were summarised using Rubin's rule.

Analyses were conducted using Stata $14 \cdot 2$ (Statacorp, College Station, TX, USA). Exact p-values are presented to indicate compatibility with null distributions but no null-hypothesis significance tests were performed.[18 $\underline{16}]$ The 'significance' of each estimate was instead evaluated by considering the clinical implications of each point estimate judged against the overall uncertainty. This corresponds with guidance from the American Statistical Association_[1917] and current practice in leading Epidemiology journals. E-values for the point estimate (E) and least extreme confidence limit (ELL) were also determined for the controlled direct effect and total indirect effect to indicate the average required effect for an unobserved confounder to explain the observed associations with the

\section{4 outcome.[18]}

A core outcomes set was not used in this analysis.

\section{Role of the funding source}

217 The Midland and North of England Stillbirth Study was funded by grant GN2156 from Action Medical

218 Research, Cure Kids and Sands. The funding sources had no role in: 1) the design or conduct of the 219 study, 2) the collection, analysis, or interpretation of the data, or 3) the preparation of the 220 manuscript and decision to submit for publication. 
Figure 1 shows the derivation of the study and analytical samples. 1024 women were recruited, including 291 cases and 733 controls. $2 \cdot 8 \%(n=8 / 291)$ of cases and $0 \cdot 6 \%(n=4 / 733)$ of controls had pre-existing diabetes and were excluded from this analysis.

Table $1 \mathrm{a}$ describes the profile of the study population. Of the 1012 total participants (283 cases and 729 controls), 94 cases and 277 controls were screened for GDM and 8 cases and 30 controls were clinically diagnosed with GDM. 35.9\% ( $n=99 / 276)$ of the cases and $32 \cdot 6 \%(n=231 / 709)$ of the controls had at least one of the four known NICE risk factors for GDM. 69.7\% (n=69/99) of these 'at risk' cases and $76 \cdot 6 \%(n=177 / 231)$ of these 'at risk' controls received screening for GDM (Figure 1). The proportion of 'at risk' women who received GDM screening varied between maternity units

232 (median=85\%, IQR=60-100, range=20-100, $\mathrm{p}<0 \cdot 0001$ ). Of those without a known NICE risk factor for 233 GDM, 13.6\% $(n=24 / 177)$ of the cases and 19.3\% $(n=92 / 478)$ of the controls were screened for GDM

234 for other unspecified reasons (likely family history of GDM). 74.3\% (n=156/210) of obese women 235 were screened for GDM, 74.7\% (n=106/142) of those self-reporting as South Asian or Black 236 Caribbean, $71 \cdot 4 \%(n=5 / 7)$ with previous history of GDM, and $90 \cdot 0 \%(n=9 / 10)$ with previous history of GDM. Fable 1 b describes the profile of the sample who received blood glucose screening.

238 'At risk' of GDM, screening for GDM, and risk of late stillbirth

The joint and distinct effects of being 'at risk' of GDM and receiving blood glucose screening for GDM on the risk of late stillbirth were examined by causal mediation analysis.-Women known to be 'at risk' of GDM overall did not havexperienced only modestly an-increased risk of late stillbirth $(\mathrm{aOR}=1.1795 \% \mathrm{Cl}=0 \cdot 87-1 \cdot 57, p=0.289)$ (Table 2$)$. This separated into a harmful direct effect of being 'at risk' of GDM and a protective indirect effect of receiving screening for GDM. Women 'at risk' of GDM who did not receive blood glucose screening experienced nearly $50 \%$ higher risks of stillbirth than women without a known risk factor $(\mathrm{aOR}=1.4495 \% \mathrm{Cl}=1 \cdot 01-2 \cdot 06, \mathrm{E}=2.24, \mathrm{ELL}=1.11, p=0.043)$ 
246 (Table 2). In contrast, women 'at risk' of GDM who did receive blood glucose screening had similar

247 risks to women without a known risk factor $(\mathrm{aOR}=0.98,95 \% \mathrm{Cl}=0 \cdot 70-1 \cdot 36,-\mathrm{p}=0.896)$ (Table 2). In

248 women without a known risk factor for GDM, the-The risk of late stillbirth was thus around one-third

249 lower for those 'at risk' of GDM who received blood glucose screening compared with those 'at risk'

250 of GDM who were not screened ( $\mathrm{OOR}=0 \cdot 68,95 \% \mathrm{Cl}=0 \cdot 47-0.98, \mathrm{E}=2.30, \mathrm{ELL}=1.21, \mathrm{P}=0.032)$

251 (Table 2).

252

FPG concentration, clinical diagnosis of GDM, and risk of late stillbirth

254 The joint and distinct effects of hyperglycaemia and receiving a clinical diagnosis of GDM (as a proxy

for specialised antenatal care) on the risk of late stillbirth were also examined by causal mediation

alysis-Overall, the risk of late stillbirth in women with a raised FPG was almost twice as high as in

women with normal FPG (aOR=1.97, 95\%Cl=0.61-6.32,$-p=0.255)$ (Table 3). This separated into a

harmful direct effect of raised FPG, and a protective indirect effect of being clinically diagnosed with

GDM and receiving specialised antenatal care. Women with a raised FPG who were not diagnosed

with GDM and therefore did not receive specialist care experienced four-times higher risks of

261 stillbirth than (undiagnosed) women with normal FPG (aOR=4.22, 95\%Cl=1.04-17.02 $\mathrm{E}=7.91$,

$262 \underline{E L L=1.24}, p=0.043$ ) (Table 3). In contrast, women with a raised FPG who were diagnosed with GDM

263 and did receive specialist care had similar risks to women with normal FPG (aOR=1.10 95\%Cl=0.31-

$264 \quad 3.91_{\llcorner}, p=0.883$ ) (Table 3). The risk of late stillbirth was thus around four-times lower for those with

265 raised FPG who were clinically diagnosed with GDM, then those with raised FPG who were not

266 clinically-diagnosed $(\mathrm{aOR}=0.26,95 \% \mathrm{Cl}=0.07-0.93, \mathrm{E}=7.15, \mathrm{ELL}=1.36)$ (Table 3).

267 The effect of FPG concentration on the risk of late stillbirth was approximately linear (Figure 2).

268 Without GDM diagnosis, each $1 \mathrm{mmol} / \mathrm{L}$ increase in FPG was associated with $61 \%$ greater risk of late

269 stillbirth (aOR=1.63, 95\%Cl=1.01-2.64, $\mathrm{p}=0.047)$. The edds ratioOR of late stillbirth for a range of FPG 
271 diagnosis and treatment for GDM are shown in Table 4.

272

273 


\section{Main findings}

276 This large, multi-centre case-control study reveals the separate and competing effects of 'risk' of 277 GDM and screening the risk of late stillbirth ${ }_{L}$ and of hyperglycaemia and clinical diagnosis of GDM 278 on the risk of late stillbirth. Using causal mediation analysis, we show how the harmful effects of 279 being 'at risk' of GDM and of raised FPG are mitigated by GDM screening and diagnosis respectively.

280 Without screening, women 'at risk' of GDM (as per NICE criteria) experienced $47 \%$ greater risk of late 281 stillbirth. For those who were screened, this excess was essentially eliminated. A similar patternalbeit with a more dramatic effect - is observed for a raised FPG. Similarly, without without GDM diagnosis, women with raised FPG experienced a four-fold greater risk of late stillbirth. For those

284 who were diagnosed and therefore are presumed to have received additional specialised care in 285

\section{Strengths and limitations}

This is the first study to explore the separate and contrasting effects of the-underlying hyperglycaemia and diagnosis of GDM (with the presumed consequent enhanced and-care) of GDA-on risk of late stillbirth. Information was collected on a large range of contextual confounding variables, and confounders requiring adjustmentwhich were identified using directed acyclic graphsDAGs. Data were relatively complete, with_96.6\% completeness across_for ethnicity, BMI, and previous histories of GDM and macrosomia; and 91.9\% for FPG among those screened. The results were also not materially different in sensitivity analyses that used multiple imputation, increasing confidence in the observed associations. 
All participants received routine care, thus less than a third were screened for GDM. It was therefore not possible to jointly examine the effects of screening, FPG concentration, and diagnosis in the full sample $(n=1012)$. The results from this from our subsample $(n=371)$ are therefore only representative of women with indications for screening; and should not be generalised to all pregnant women. Unfortunately, we did not have complete information on the NICE criteria for screening, as family history of diabetes was not collected. Nor do we know the reasons why the quarter of women 'at risk' of GDM were not screened. Unrecorded differences in risk profile, or in the participant's engagement with health services, may introduce bias. However, the observed differences in screening levels between maternity units suggest these may reflect true variations in UK clinical practice.

Our analyses and interpretations focussed on effect estimates, not null-hypothesis significance tests, as the latter are strongly discouraged within observational studies [1816]. There are hence no formal risks of type I or type II errors. For some subgroups-however, particularly women with diagnosed GDM, our sample included very small numbers ${ }_{2}$ to imprecise estimatesleading to substantial uncertainty that should be appreciated when interpreting absolute effect sizes.

Causal mediation analysis makes several assumptions, including that the exposure(s) and mediator(s) have a causal effect on the outcome. We believe these are plausible, and our assumptions are clearly outlined in our DAGs (Supplementary-Figure $\underline{\mathbf{s}} 1$ ). Nevertheless, for both GDM screening and diagnosis, the hypothesised effects depend on presumed enhanced clinical response to diagnosis, without which we would not expect to see a benefit.

Unbiased estimates of causal effects require no unobserved confounding. Family history of GDM may therefore bias the estimated causal effects of FPG and diagnosis of GDM on risk of stillbirth. Mediation analyses are also highly susceptible to intermediate confounding from unobserved causes of both mediator(s) and outcome(s),-[2119] although we could not identify any such variables for the relationships examined. Our E-values suggest that considerable confounding would be necessary to 
explain the observed point estimates; although modest confounding could explain the conservative

estimates from our lower confidence limits.

Interpretation

326 Few previous studies have explored the separate and contrasting effects of raised blood glucose, as

327 a harmful exposure, and the receipt of specialised care, as a mitigating factor; making it difficult to meaningfully compare results. Our findings do however support previous studies which have suggested that a diagnosis of GDM leads to improved perinatal outcomes in women with raised blood glucose $[8 \underline{5}, 20 \underline{20}]$. Few studies have been large enough to explore a relationship with stillbirth specifically, Aberg et al. (1997) found very little difference in the risk of stillbirth between women with and without diagnosed GDM $(\mathrm{OR}=1 \cdot 33,95 \% \mathrm{Cl}=0 \cdot 64-2 \cdot 77)$, but identified much higher risks of intrauterine death in the previous pregnancy of women subsequently diagnosed with GDM $(\mathrm{OR}=1.56,95 \% \mathrm{Cl}=1.12-2.19)$ [ 2221 ]. Similarly Kodoma at al. (2013) found that when new, more stringent GDM criteria, were retrospectively applied to a cohort of 318 stillbirths, the prevalence of GDM increased 5.7-times from $2.4 \%$ to $13.5 \%$ in women who had unexplained stillbirths.[2322]

337 These studies support our observations that untreated hyperglycaemia confers a greater risk of

338 stillbirth, thiswhich is greatly reduced by a clinical diagnosis with GDM. It is unclear aspect has the greatest impact on outcome following diagnosis of GDM, from the additional antenatal care, help-stabilising blood sugar levels, or timing of birthdelivery. Our study is unfortunately too-small and does not have the relevant data to further investigate these effects.

There continues to be debate about the merit of universal versus targeted screening [ $24 \underline{23}]$ and the ideal threshold for the diagnosis of GDM. In our sample, $2 \cdot 8 \%$ of cases and $5 \cdot 1 \%$ of controls were diagnosed with GDM. Although prevalence proportions vary greatly between populations, proportions of $\geq 5 \%$ are usual,[2524] suggesting potential under-diagnosis. This would correspond with findings from the 2015 UK Confidential Enquiry into Term Antepartum Stillbirths [2]. The NICE

347 criteria for the diagnosis of GDM however changed in 2015, during the conduct of this study, from 
FPG $\geq 7.0 \mathrm{mmol} / \mathrm{L}$ to $\geq 5.6 \mathrm{mmol} / \mathrm{L},[3,-26 \underline{25}]$ which may explain a lower prevalence. The NICE

349 reportedly selected their new FPG criterion to reflect increases in perinatal morbidity, specifically

350 large-for-gestational-age at lower levels of FPG, [1211] although it remains higher than the FPG

$351 \geq 5 \cdot 1 \mathrm{mmol} / \mathrm{L}$ threshold recommended by the International Association of Diabetes and Pregnancy

352 Study Groups (IADPSG) [26].

353 For those 'at risk' of GDM, we found a linear effect of increasing FPG on the risk of late stillbirth,

354 suggesting that all women with an increased risk of GDM may benefit from optimising their glucose

355 control, regardless of whether they meet the threshold for diagnosis. which is in line with the

356 findings of a continuous relationship between blood glucose levels and adverse pregnancy in the

357 Hyperglycemia and Adverse Pregnancy Outcome (HAPO) study.-[27]-_Our data do not therefore

358 support the biological justification of one threshold over another, instead suggesting that it may be

359 best determined by a pragmatic balance of resources required for available resource. It has been

360 suggested that the increased antenatal workloads and health costs required for with more stringent

361 GDM diagnostic criteria are offset byainst the reduced costs of improved perinatal outcome.

362 [27르]: Different resource pressures almost certainly explain the variations in screening and

363 diagnostic practices that we observed between maternity units, despite uniform governance from

364 NICE guidelines. Our results suggest that universal adherence to NICE guidelines for the screening

365 and diagnosis of GDM would greatly reduce the excess risk of stillbirth due to raised FPG in the

366 population. To lower this risk further - especially in individuals on the border of diagnosis - it may

367 also be worth exploring a moreconsidering a graded stepped-approach to the care and management

368 of blood glucose control in pregnant women, rather than relying on a single diagnostic

369 thresholdeonsistent with current notions on stratified medicine [28].

370

371 Conclusion 
372 Women 'at risk' of GDM and/or with raised FPG experience higher risk of late stillbirth. With

373 appropriate screening, diagnosis, managementand the presumed management and care practices

374 that result, and care practices-these risks can be largely mitigated. However, variation in practice

375 leaves many women with borderline hyperglycaemia exposed to avoidably elevated risk. If the UK is

376 to improve its record for preventable stillbirth, and have a hope of achieving ambitious government

377 targets [29] then all women 'at risk' of GDM and/or with raised FPG must receive the care

378 recommended by NICE. Further research needs to address the economic and practical implications

379 of implementing different thresholds of FPG to diagnose GDM._, in particular consider the number of

380 women needed to be screened to prevent one stillbirth if the threshold of $5.1 \mathrm{mmol} / \mathrm{L}$ were to be

381 implemented. 
392

393

406

407

Disclosure of interests

All authors declare that they have no competing interests

\section{Contribution to authorship}

$A H, T S, B M, D R, E M$, and LM contributed to all aspects of the study design and obtained funding. JB coordinated the running of the study. PWGT performed the data analysis with input from TS, ML and JT. TS drafted the manuscript. All authors were involved in interpreting the data and critically reviewing manuscript drafts. All authors gave approval for the final version of the manuscript. The authors thank all the participants who participated in interviews in order to help us better understand stillbirth.

\section{Ethics committee Approval}

This study was reviewed by NRES Committee North West - Greater Manchester Central Reference (13/NW/0874) approval granted 2013, with all participants providing written consent to take part in the study.

\section{Funding}

The Midland and North of England Stillbirth Study was funded by grant GN2156 from Action Medical Research, Cure Kids and Sands. AH receives salary support from Tommy's and the National Institute of Health Research (Clinician Scientist Award CS-13-009). EM and JT were supported by Cure Kids. PWGT is supported by The Alan Turing Institute [EP/N510129/1]. The funders had no role in the study design, data collection and analysis, decision to publish, or preparation of the manuscript. The views expressed in this manuscript are entirely those of the authors and do not necessarily reflect those of the funders. 
409 [1] Flenady V, Wojcieszek AM, Middleton P, Ellwood D, Erwich JJ, Coory M et al (2016) 410 Stillbirths: recall to action in high-income countries. Lancet 387: 691-702

411 [2] Draper E, Kurinczuk J, Kenyon S, on behalf of MBRRACE-UK. MBRRACE-UK Perinatal 412 Confidential Enquiry (2015) MBRRACE-UK 2015 Perinatal Confidential Enquiry Term, singleton, 413 normally-formed, antepartum stillbirth. Leicester

414 [3] NICE National Institute for Health and Care Excellence (2015) Diabetes in pregnancy: 415 management from preconception to the postnatal period (NG3).

416 [4] Lapolla A, Dalfrà MG, Bonomo M, Parretti E, Mannimo D, Mello G et al. (2009) Gestational 417 diabetes mellitus in Italy: A multicenter study. Eur J Obstet Gynecol Reprod Biol 145: 149-153

418 [5] Crowther CA, Hiller JE, Moss JR, McPhee AJ, Jeffries WS, Robinson JS (2005) Effect of 419 treatment of gestational diabetes mellitus on pregnancy outcomes. N Engl J Med 352: 2477-2486

420 [6] Tennant PWG, Glinianaia SV, Bilous RW, Rankin J, Bell R (2014) Pre-existing diabetes, 421 maternal glycated haemoglobin, and the risks of fetal and infant death: a population-based study. 422 Diabetologia 57: 285-294

423

424 [7] Schmidt MI, Duncan BB, Reichelt AJ, Branchtein L, Matos MC, Costa e Forti A et al. (2001) 425 Gestational Diabetes Mellitus Diagnosed With a 2-h 75-g Oral Glucose Tolerance Test and Adverse 426 Pregnancy Outcomes. Diabetes Care 24: 1151-1155

427 [8] Peticca P, Keely EJ, Walker MC, Yang Q, Bottomley J (2009) Pregnancy Outcomes in Diabetes 428 Subtypes: How Do They Compare? A Province-based Study of Ontario, 2005-2006. J Obstet Gynaecol 429 Canada 31: 487-496

430 [9] Metzger BE, Buchanan TA, Coustan DR, de Leiva A, Dunger DB, Hadden DR et al. (2007) 431 Summary and recommendations of the Fifth International Workshop-Conference on Gestational 432 Diabetes Mellitus. Diabetes Care 30: S251 - 260 
433 [10] Coustan DR, Lowe LP, Metzger BE, Dyer AR, International Association of Diabetes and 434 Pregnancy Study G (2010) The Hyperglycemia and Adverse Pregnancy Outcome (HAPO) study: 435 paving the way for new diagnostic criteria for gestational diabetes mellitus. Am J Obstet Gynecol 436 202: 654.e651-656

437

438 _[113] NCC-WCH (National Collaborating Centre for Women's and Children's Health) (2015) 439 Diabetes in pregnancy: Management of diabetes and its complications from preconception to the 440 postnatal period, NICE

441 [12] Heazell AEP, Li M, Budd J,Thompson JMD, Stacey T, Cronin R et al (2018) Association 442 between maternal sleep practices and late stillbirth - findings from a stillbirth case-control study. 443 BJOG 125: 254-262

444 [1513] Platts J, Mitchell EA, Stacey T, Martin B, Roberts R, McCowan L et al. (2014) The Midland and 445 North of England Stillbirth Study (MiNESS). BMC Pregnancy Childbirth 14: 171

446 [14] Mitchell, E. A. (2015). Proceedings of 2011 Stillbirth Summit. BMC Pregnancy and Childbirth $447 \quad$ 15(Suppl 1): A2-A2.

[1715] VanderWeele TJ (2016) Mediation Analysis: A Practitioner's Guide. Annu Rev Public Health $449 \quad 37: 17-32$

450 [1816] Greenland S, Senn S, Rothman K, Carlin JB, Poole C, Goodman SN etet al. (2016) Statistical 451 tests, $\mathrm{P}$ values, confidence intervals, and power: a guide to misinterpretations. Eur J Epidemiol 31 : $452 \quad 337-350$

453 [1917] Wasserstein RL, Lazar NA (2016) The ASA's Statement on p-Values: Context, Process, and 454 Purpose. The American Statistician 70: 129-133

455 [2018] VanderWeele, T. J. and P. Ding (2017). Sensitivity Analysis in Observational Research:

$456 \quad$ Introducing the E-Value. Ann Intern Med 167(4): 268-274. 
457 [19] Langer O, Yogev Y, Most O, Xenakis EMJ (2005) Gestational diabetes: The consequences of not 458 treating. Am J Obstet Gynecol 192: 989-997

459 [2120] Richiardi L, Bellocco R, Zugna D (2013) Mediation analysis in epidemiology: methods, 460 interpretation and bias. Int J Epidemiol, 42: 1511-9

461 [Z221] Aberg A, Rydhstrom H, Kallen B, et at.Kallen K (1997) Impaired glucose tolerance during 462 pregnancy is associated with increased fetal mortality in preceding sibs. Acta Obstet Gynecol Scand $463 \quad 76: 212-217$

464 [2322] Kodama Y, Sameshima H, Ohashi M, Ikenoue T (2013) Impact of new gestational diabetes 465 mellitus criteria on stillbirth: a regional population-based study in Japan. J Obstet Gynaecol Res 39: $466 \quad 1242-1245$

467 [Z4르] Farrar D, Fairley L, Wright J, Tuffnell D, Whitelaw D, Lawlor DA (2014) Evaluation of the 468 impact of universal testing for gestational diabetes mellitus on maternal and neonatal health 469 outcomes: a retrospective analysis. BMC Pregnancy Childbirth 14: 317

470 [25르] Farrar D, Duley L, Medley N, Lawlor DA (2015) Different strategies for diagnosing gestational 471 diabetes to improve maternal and infant health. Cochrane Database Syst Rev 1: CD007122

472 [Z625] NICE National Institute for Health and Clinical Excellence (2008) Diabetes in pregnancy: 473 management from preconception to the postnatal period (CG63).

474 [26] International Association of Diabetes and Pregnancy Study Groups Consensus Panel (2010) 475 International association of diabetes and pregnancy study groups recommendations on the 476 diagnosis and classification of hyperglycemia in pregnancy. Diabetes Care; 33: 676-682.

477 [2727] The HAPO Study Cooperative Research Group (2008) Hyperglycemia and Adverse Pregnancy 478 Outcomes. N Engl J Med 358: 1991-2002

479 [28] Duran A, Sáenz S, Torrejón MJ, et al.Bordiu E, del Valle L, Galindo M et al(2014) Introduction of 480 IADPSG Criteria for the Screening and Diagnosis of Gestational Diabetes Mellitus Results in Improved 481 Pregnancy Outcomes at a Lower Cost in a Large Cohort of Pregnant Women: The St. Carlos 482 Gestational Diabetes Study. Diabetes Care 37: 2442-2450 
483 [zg29] Hunt J (2015) New ambition to halve rate of stillbirths and infant deaths. Available from 484 https://www.gov.uk/government/news/new-ambition-to-halve-rate-of-stillbirths-and-infant-deaths,

485 accessed $5 / 3 / 18$ 
1,024 Total recruited

291 Cases

733 Controls

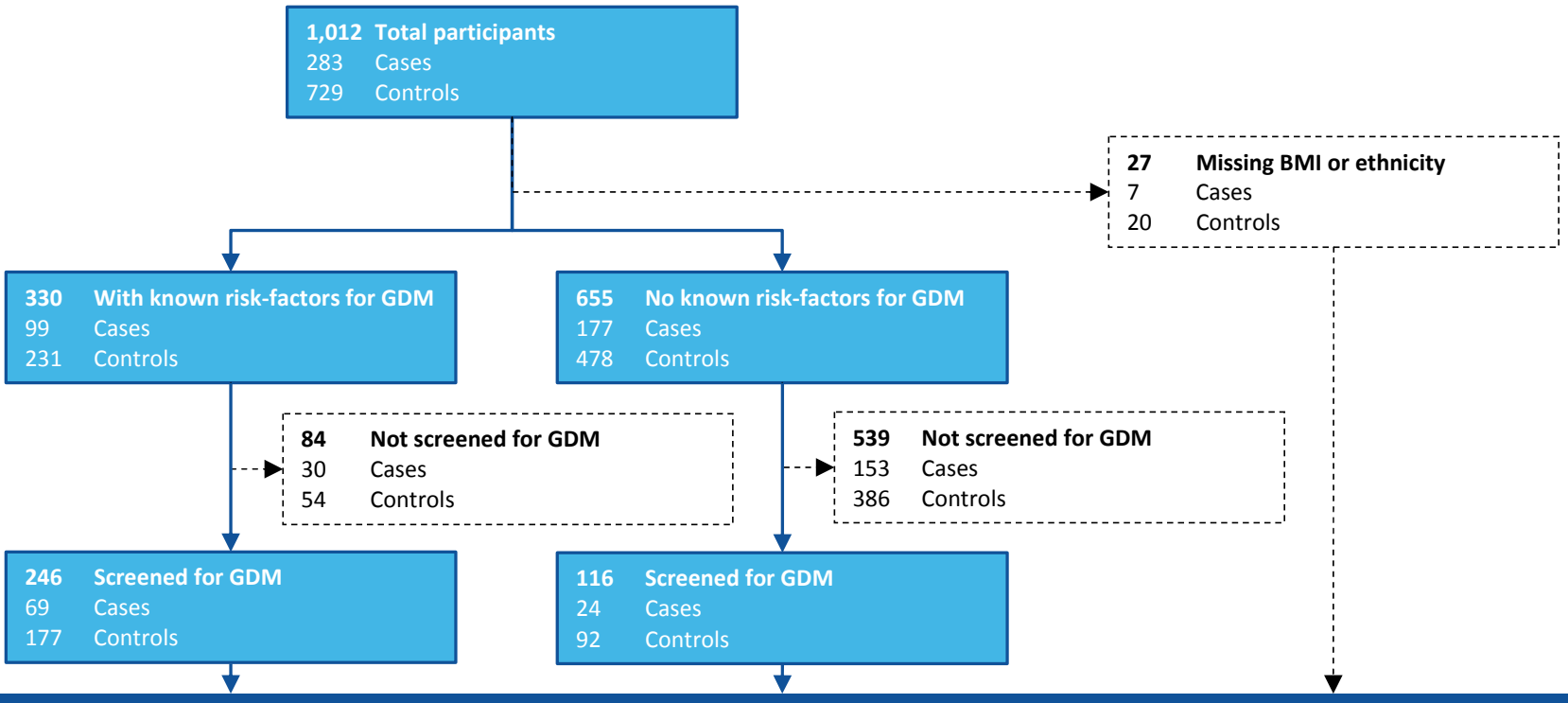

Total screened for GDM (N=371)

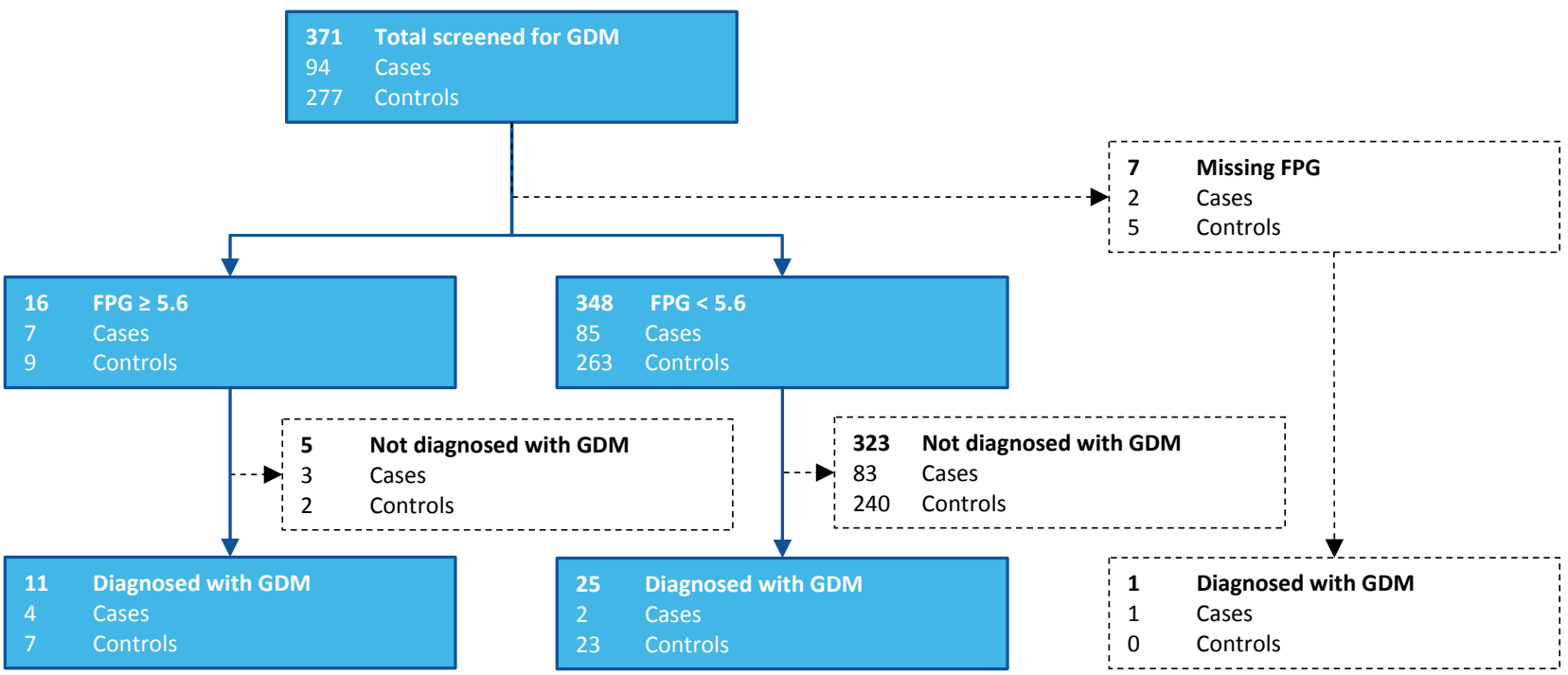

Figure 1 Derivation of the study and analytic sample(s). 


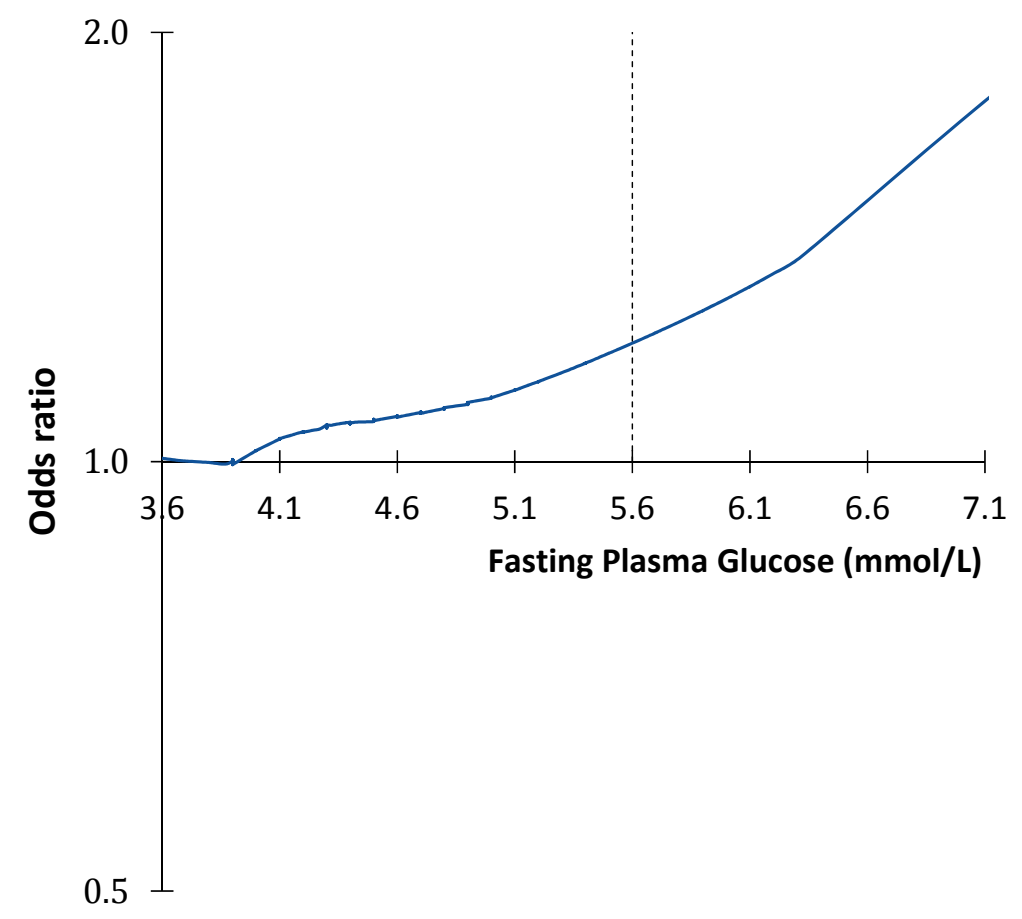

Figure 2: Unconditional odds ratio for late stillbirth across typical values of fasting plasma glucose (FPG), relative to women with FPG $<4.1 \mathrm{mmol} / \mathrm{L}$.

Dotted line indicates current FPG threshold recommended by NICE.[3] 
Table 1. Risk factors, screening and FPG concentration

\begin{tabular}{|c|c|c|c|c|c|c|c|c|c|c|}
\hline \multirow{3}{*}{ NICE GDM risk variables } & \multicolumn{4}{|c|}{$\begin{array}{c}\text { Total participants }(\mathrm{N}=1012) \\
\mathrm{N}(\%)\end{array}$} & \multicolumn{6}{|c|}{$\begin{array}{c}\text { Screened for GDM (N=371) } \\
\qquad(\%)\end{array}$} \\
\hline & $\begin{array}{c}\text { Cases } \\
(\mathrm{N}=283)\end{array}$ & $\begin{array}{l}\text { Controls } \\
(\mathrm{N}=729)\end{array}$ & \multicolumn{2}{|c|}{$\begin{array}{c}\text { All } \\
(\mathrm{N}=1012)\end{array}$} & \multicolumn{2}{|c|}{$\begin{array}{l}\text { Cases } \\
(\mathrm{N}=94)\end{array}$} & \multicolumn{2}{|c|}{$\begin{array}{l}\text { Controls } \\
(\mathrm{N}=277)\end{array}$} & \multicolumn{2}{|c|}{$\begin{array}{c}\text { All } \\
(\mathrm{N}=371)\end{array}$} \\
\hline \multirow{2}{*}{\multicolumn{11}{|c|}{ Ethnicity }} \\
\hline & & & & & & & & & & \\
\hline White & $227(81.4)$ & $590(82.8)$ & 817 & $(82.4)$ & 60 & $(64.5)$ & 182 & $(67.7)$ & 242 & $(66.9)$ \\
\hline South Asian & $40(14.3)$ & $93(13.0)$ & 133 & $(13.4)$ & 27 & $(29.0)$ & 71 & $(26.4)$ & 98 & $(27.1)$ \\
\hline Black Caribbean & $1(0.4)$ & $8(1.1)$ & 9 & $(0.9)$ & 1 & $(1.1)$ & & $(3.4)$ & 8 & $(2.2)$ \\
\hline Other & $11(3.9)$ & $22(3.1)$ & 33 & (3.3) & 5 & (5.4) & 9 & (2.6) & 14 & $(3.8)$ \\
\hline Missing & 4 & 16 & 20 & & 1 & & 8 & & 9 & \\
\hline \multicolumn{11}{|l|}{ BMI $\left(\mathrm{kg} / \mathrm{m}^{2}\right)$} \\
\hline <18.5 (underweight) & $9(3.2)$ & $23(3.2)$ & 32 & (3.2) & 3 & $(3.2)$ & 8 & (2.9) & 11 & $(3.0)$ \\
\hline $18.5-24.9$ (recommended) & $111(39.9)$ & $342(47.5)$ & 453 & $(45.4)$ & 19 & $(20.2)$ & 90 & $(33.0)$ & 109 & $(29.7)$ \\
\hline $25-29.9$ (overweight) & $88(31.7)$ & $215(29.9)$ & 303 & $(30.4)$ & 22 & $(23.4)$ & 69 & (25.3) & 91 & $(24.8)$ \\
\hline$\geq 30$ (obese) & $70(25.2)$ & $140(19.4)$ & 210 & $(21.0)$ & 50 & $(53.2)$ & 106 & $(38.8)$ & 156 & $(42.5)$ \\
\hline Missing & 5 & 9 & 14 & & 0 & & 4 & & 4 & \\
\hline \multicolumn{11}{|l|}{ Previous GDM } \\
\hline No & $282(99.6)$ & $723(99.2)$ & 1005 & $(99.3)$ & 93 & $(98.9)$ & 273 & $(98.6)$ & 366 & $(98.7)$ \\
\hline Yes & $1(0.4)$ & $6(0.8)$ & 7 & $(0.7)$ & 1 & $(1.1)$ & 4 & $(1.4)$ & 5 & $(1.4)$ \\
\hline \multicolumn{11}{|l|}{ Previous macrosomic infant } \\
\hline No & $282(99.7)$ & $720(98.8)$ & 1002 & $(99.0)$ & 94 & $(100.0)$ & 268 & $(96.8)$ & 362 & (97.6) \\
\hline Yes & $1(0.4)$ & $9(1.2)$ & 10 & $(1.0)$ & 0 & $(0.0)$ & 9 & (3.3) & 9 & $(2.4)$ \\
\hline \multicolumn{11}{|l|}{ 'At risk' of GDM ${ }^{a}$} \\
\hline No & $177(64.1)$ & $478(67.4)$ & 655 & $(66.5)$ & 24 & $(25.8)$ & 92 & $(34.2)$ & 116 & $(32.0)$ \\
\hline Yes & $99(35.9)$ & $231(32.6)$ & 330 & (33.5) & 69 & $(74.2)$ & 177 & $(65.8)$ & 246 & $(68.0)$ \\
\hline Missing & 7 & 20 & 27 & & 1 & & 8 & & 9 & \\
\hline \multicolumn{11}{|l|}{ FPG concentration ( $\mathrm{mmol} / \mathrm{L})$} \\
\hline$<4.10$ & & & & & 17 & $(18.5)$ & 51 & $(18.8)$ & 68 & $(18.7)$ \\
\hline $4.10-4.59$ & & & & & 44 & $(47.8)$ & 129 & $(47.4)$ & 173 & $(47.5)$ \\
\hline $4.60-5.09$ & & & & & 21 & $(22.8)$ & 62 & $(22.8)$ & 83 & $(22.8)$ \\
\hline $5.10-5.59$ & & & & & 3 & (3.3) & 21 & $(7.7)$ & 24 & $(6.6)$ \\
\hline $5.60-6.09$ & & & & & 3 & (3.3) & & (1.8) & 8 & $(2.2)$ \\
\hline$\geq 6.10$ & & & & & 4 & (4.4) & 4 & (1.5) & 8 & $(2.2)$ \\
\hline Missing & & & & & 2 & & 5 & & 7 & \\
\hline \multicolumn{11}{|l|}{ GDM diagnosed } \\
\hline No & & & & & 87 & $(92.6)$ & 247 & $(89.2)$ & 334 & $(90.0)$ \\
\hline Yes & & & & & 7 & $(7.5)$ & 30 & (10.8) & 37 & $(10.0)$ \\
\hline
\end{tabular}

'Women known to be 'at risk' of GDM and who are indicated for screening comprise those who reported their ethnic origin as South Asian, black Caribbean, had body mass index $\geq 30 \mathrm{Kg} / \mathrm{m}^{2}$, or who had a previous pregnancy affected by gestational diabetes or macrosomic birth $(>4.5 \mathrm{~kg})$. 
Table 2 Estimated effects of 'at risk' of GDM ${ }^{a}$ and screening for GDM on risk of late stillbirth

\begin{tabular}{|c|c|c|c|c|c|}
\hline Effect estimated & Exposure regime & Reference regime & $\mathrm{aOR}^{\mathrm{b}}$ & $(95 \% \mathrm{Cl})$ & $\begin{array}{l}\text { E-value } \\
\text { (lower } \mathrm{Cl} \text { ) }\end{array}$ \\
\hline Total effect & $\begin{array}{l}\text { 'At risk' of GDM } \\
+ \text { screened for GDM }\end{array}$ & $\begin{array}{l}\text { Not 'at risk' + } \\
+ \text { not screened }\end{array}$ & 0.98 & $(0 \cdot 70-1 \cdot 36)$ & \\
\hline Natural effect & $\begin{array}{l}\text { 'At risk' of GDM } \\
+\quad \text { 'natural' chance }\end{array}$ & $\begin{array}{c}\text { Not 'at risk' + } \\
\text { of }+ \text { not screened }\end{array}$ & $1 \cdot 17$ & $(0 \cdot 87-1 \cdot 57)$ & \\
\hline Controlled direct effect & $\begin{array}{l}\text { 'At risk' of GDM } \\
+ \text { not screened for GDM }\end{array}$ & $\begin{array}{l}\text { Not 'at risk' + } \\
+ \text { not screened }\end{array}$ & $1 \cdot 44$ & $(1 \cdot 01-2 \cdot 06)$ & $2.24(1.11)$ \\
\hline Total indirect effect & $\begin{array}{l}\text { 'At risk' of GDM } \\
+ \text { screened for GDM }\end{array}$ & $\begin{array}{l}\text { 'At risk' of GDM + } \\
\text { + not screened }\end{array}$ & 0.68 & $(0.47-0.97)$ & $2.30(1.21)$ \\
\hline Natural indirect effect & $\begin{array}{l}\text { 'At risk' of GDM } \\
+\quad \text { 'natural' chance }\end{array}$ & $\begin{array}{l}\text { 'At risk' of GDM + } \\
\text { of + not screened }\end{array}$ & $0 \cdot 81$ & $(0.67-0.98)$ & \\
\hline
\end{tabular}

${ }^{a}$ Known risk factors for GDM (indicated by NICE for blood glucose screening) comprise South Asian or black Caribbean ethnicity, body mass index $\geq 30 \mathrm{Kg} / \mathrm{m}^{2}$, and previous pregnancy affected by gestational diabetes or macrosomic birth (>4.5kg).

${ }^{\mathrm{b}}$ Models included the exposure ('at risk' of GDM) and mediator (screened for GDM) only, as all partial confounding variables were also partial mediators. 
Table 3 Estimated effects of FPG concentration and clinical diagnosis of GDM on risk of late stillbirth

\begin{tabular}{|c|c|c|c|c|c|}
\hline Effect estimated & Exposure regime & Reference regime & $\mathrm{aOR}^{\mathrm{a}}$ & $(95 \% \mathrm{Cl})$ & $\begin{array}{l}\text { E-value } \\
\text { (lower } \mathrm{Cl})\end{array}$ \\
\hline Total effect & $\begin{array}{l}\geq 5 \cdot 6 \mathrm{mmol} / \mathrm{L}^{\mathrm{b}} \\
+ \text { diagnosed with GDM }\end{array}$ & $\begin{array}{l}<5.6 \mathrm{mmol} / \mathrm{L} \\
+ \text { Not diagnosed }\end{array}$ & $1 \cdot 10$ & $(0 \cdot 31-3 \cdot 91)$ & \\
\hline Natural effect & $\begin{array}{l}\geq 5 \cdot 6 \mathrm{mmol} / \mathrm{L}^{\mathrm{b}} \\
+\quad \text { 'natural' }\end{array}$ & $\begin{array}{c}<5.6 \mathrm{mmol} / \mathrm{L} \\
\text { of }+ \text { Not diagnosed }\end{array}$ & 1.97 & $(0 \cdot 61-6 \cdot 32)$ & \\
\hline Controlled direct effect & $\begin{array}{l}\text { Ninnnncir } \\
\geq 5 \cdot 6 \mathrm{mmol} / L^{b} \\
+ \text { not diagnosed with GDM }\end{array}$ & $\begin{array}{l}<5.6 \mathrm{mmol} / \mathrm{L} \\
+ \text { Not diagnosed }\end{array}$ & $4 \cdot 22$ & $(1 \cdot 04-17 \cdot 02)$ & $7.91(1.24)$ \\
\hline Total indirect effect & $\begin{array}{l}\geq 5 \cdot 6 \mathrm{mmol} / \mathrm{L}^{\mathrm{b}} \\
+ \text { diagnosed with GDM }\end{array}$ & $\begin{array}{l}\geq 5 \cdot 6 \mathrm{mmol} / \mathrm{L}^{\mathrm{b}} \\
+ \text { Not diagnosed }\end{array}$ & $0 \cdot 26$ & $(0.07-0.93)$ & $7.15(1.36)$ \\
\hline Natural indirect effect & $\begin{array}{l}\geq 5 \cdot 6 \mathrm{mmol} / \mathrm{L}^{\mathrm{b}} \\
+\quad \text { 'natural' }\end{array}$ & $\begin{array}{c}\geq 5 \cdot 6 \mathrm{mmol} / \mathrm{L}^{\mathrm{b}} \\
\text { of }+ \text { Not diagnosed }\end{array}$ & 0.47 & $(0 \cdot 23-0 \cdot 96)$ & \\
\hline
\end{tabular}

${ }^{a}$ Models included the exposure (binary FPG concentration), mediator (clinical diagnosis of GDM), and all observed variables in the minimum sufficient adjustment set (maternal ethnicity, socio-economic circumstances, family history of GDM, height, weight, age, parity, previous histories of GDM and macrosomia, and smoking).

${ }^{\mathrm{b}}$ NICE criteria for diagnosis of GDM 
Table 4 Estimated odds ratio for late stillbirth for different levels of FPG - with and without diagnosis and treatment for GDM - relative to (undiagnosed) women with $\mathrm{FPG}<4.1 \mathrm{mmol} / \mathrm{L}$

\begin{tabular}{|c|c|c|}
\hline FPG & $\begin{array}{l}\text { No diagnosis \& treatment } \\
\qquad \operatorname{aOR}^{\mathrm{a}}(95 \% \mathrm{Cl})\end{array}$ & $\begin{array}{l}\text { Diagnosed \& treated } \\
\text { aOR }^{a}(95 \% \mathrm{Cl})\end{array}$ \\
\hline $4 \cdot 1$ & $1.15(1.01-1 \cdot 30)$ & \\
\hline $4 \cdot 6$ & $1.46(1.01-2 \cdot 10)$ & \\
\hline $5 \cdot 1$ & $1.87(1.02-3.42)$ & \\
\hline $5 \cdot 6$ & $2 \cdot 39(1.03-5 \cdot 55)$ & $0.61(0.21-1 \cdot 72)$ \\
\hline $6 \cdot 1$ & $3.05(1.03-9.02)$ & $0.78(0.26-2 \cdot 34)$ \\
\hline $6 \cdot 6$ & $3.89(1.03-14.65)$ & $1.00(0.30-3 \cdot 33)$ \\
\hline $7 \cdot 1$ & $4.97(1.04-23 \cdot 80)$ & $1.27(0.33-4.90)$ \\
\hline $7 \cdot 6$ & $6.34(1.04-38.67)$ & $1.62(0.35-7 \cdot 40)$ \\
\hline
\end{tabular}

${ }^{a}$ Models included the exposure (continuous FPG concentration), mediator (clinical diagnosis of GDM), and all observed variables in the minimum sufficient adjustment set (maternal ethnicity, socio-economic circumstances, family history of GDM, height, weight, age, parity, previous histories of GDM and macrosomia, and smoking). 